\title{
Maternal mortality at a tertiary care teaching hospital of rural Assam: A retrospective study with special emphasis on time interval from admission to death along with impact of late referral
}

\author{
Binoy Kumar Borah, Nikhil Ranjan Rajkhowa \\ Correspondence: Dr Binoy Kumar Borah, Assistant Professor, Department of Obstetrics \\ and Gynaecology, Jorhat Medical College; Email : borahbinoykumar@yahoo.in
}

Distributed under Creative Commons Attribution-Share Alike 4.0 International.

\begin{abstract}
Objectives: To assess the maternal mortality ratio, causes of maternal death, time interval from admission to death with impact of late referral at a tertiary care teaching hospital of rural Assam. Method: A retrospective hospital based study of 88 maternal deaths over a period of three years from January 2013 to December 2015. The information regarding time interval between admission and death, details of referral status, demographic profile and reproductive parameters are collected and results are analyzed by using percentage and proportions. Results: Over the study period, there were 20333 deliveries giving maternal mortality ratio (MMR) of 446.38 per 100,000 live births. Most of the women died $(n=65,73.87 \%)$ within 12 hours of admission suggesting majority of the patients arrived at the tertiary care hospitals quite late. Most of the deaths occurred in the age group of below 25 years $(n=69,78.4 \%)$ and most of them are primi gravida $(n=62,70.4 \%)$. Most of the cases were unbooked, 65(72.73\%). The number of direct causes were $(n=76,86.4 \%)$ in comparison to the indirect causes $(n=12,23.86 \%)$. The leading direct cause was eclampsia $(n=40,45.45 \%)$ whereas indirect leading cause was anaemia $(n=11,12.50 \%)$. Conclusion: Most of these maternal deaths were preventable by proper ante natal care, early referral, well equipped transport facilities and by more equipped tertiary care.
\end{abstract}

Keywords: Maternal death, early referral, ANC, eclampsia.

Over 600,000 maternal deaths occur each year worldwide where almost $99 \%$ is contributed by the developing countries. India is among those countries which has a very high maternal mortality ratio (MMR), currently estimated as 174 per 100,000 live birth which is still far above the desired goal of 100 per 100,000 live birth as per the objectives of Millenium Development Goals (MDG)[1]. Remarkably a population based survey carried out in India which cover longitudinal surveillance and complete coverage of vital events reported a MMR of 320 per 100,000 live birth in rural areas of India including Assam also with a

Received: $30^{\text {th }}$ June 2016. Accepted: $28^{\text {th }}$ August 2016.

Borah BK, Rajkhowa NR Maternal mortality at a tertiary care teaching hospital of rural Assam: A retrospective study with special emphasis on time interval from admission to death along with impact of late referral. The New Indian Journal of OBGYN. 2017; 3(2): 79-85 
higher MMR of 328 (2012) within the country [2].

Pregnancy though it is a physiological state always carries high risk of maternal mortality and morbidity which has a serious implication to the family, society and the nation. Morever MMR indicates as a very sensitive index that reflects the poverty, socioeconomic status, literacy, social upliftment, economic growth, quality of health care provided to the women and women empowerment status of the nation also [3-5].

The present study was conducted to review the existing maternal mortality ratio, causes of maternal death, time of interval from the admission to death, status of referral system with transport facility, impact of delayed referral at a tertiary care teaching hospital of rural Assam so that corrective and cumulative steps can be suggested for the concerned departments like health and family welfare, social welfare, education, welfare of tribes etc. so as to reach the goal within the stipulated time period.

\section{Materials and Methods}

This retrospective hospital based study was carried out in the Obstetrics and Gynaecology Department of Jorhat Medical College and Hospital, a rural tertiary level health care referral centre in Assam, India over a period of 3 years from January 2013 to December 2015. A total number of 88 maternal deaths were analyzed with the special emphasis on sociodemographic profile of the patient, prenatal care, parity and cause of death. We also analyzed the time interval from admission to death, trimester of pregnancy at the time of death, communication facility and delay if any in reaching the tertiary care centre from primary care centre. All necessary data were collected maternal death register, bed head tickets, data from MRD department, and maternal death review meeting register. Results were analyzed by using percentage and proportion.

\section{Inclusion criteria}

- Death resulting from complications of pregnancy itself, labour, or the puerperium or within 42 days of termination of pregnancy irrespective of site and duration of pregnancy.
- Death resulting from disease present from before or which developed during pregnancy that was aggravated by the physiological changes of pregnancy.

\section{Exclusion criteria}

- Death resulting from other causes except mentioned above, including suicide and homicide.

\section{Results and Observations}

In this study, total live births were 19716 and total

\begin{tabular}{|l|l|l|l|l|}
\hline \multicolumn{5}{|c|}{ Table 1: Year wise maternal mortality rate } \\
\hline Year & $\begin{array}{l}\text { Total } \\
\text { deliveries }\end{array}$ & $\begin{array}{l}\text { Live } \\
\text { birth }\end{array}$ & $\begin{array}{l}\text { Maternal } \\
\text { death }\end{array}$ & MMR \\
\hline 2013 & 6178 & 5994 & 32 & 533 \\
\hline 2014 & 6688 & 6473 & 26 & 402 \\
\hline 2015 & 7467 & 7249 & 30 & 413 \\
\hline
\end{tabular}

Table 2: Distribution of maternal deaths according to socio- demographic characteristics.

\begin{tabular}{l|l|}
$\begin{array}{l}\text { Socio-demographic } \\
\text { characteristics }\end{array}$ & $\begin{array}{l}\text { Number of maternal } \\
\text { deaths (Percentage) }\end{array}$ \\
\hline Age in years & $32(36.36 \%)$ \\
\hline$<19$ & $37(42.04 \%)$ \\
\hline $19-24$ & $13(14.77 \%)$ \\
\hline $25-29$ & $4(4.54 \%)$ \\
\hline $30-34$ & $2(2.27 \%)$ \\
\hline$\geq 35$ & 0 \\
\hline Socioeconomic status & \multicolumn{2}{|l}{} \\
\hline Upper & $1(1.13 \%)$ \\
\hline Upper middle & $6(6.81 \%)$ \\
\hline Lower middle & $16(18.18 \%)$ \\
\hline Upper lower & $65(73.86 \%)$ \\
\hline Lower & \multicolumn{2}{|l}{} \\
\hline
\end{tabular}

no. of maternal deaths were 88 in the above mentioned period giving rise to an MMR of 446 which is found quite high in comparison to the national level. Table 1 shows year wise no. of maternal death and MMR from 2013 to 2015 and it is observed that in our study period, maternal death and MMR was almost equivalent in the years 2014 and 2015. 
Table 2 shows that out of total 88 deaths, 37 (42.04\%) were in the age group of 19-24 years followed by 32 $(36.36 \%)$ deaths in $<19$ years. Majority of maternal deaths $65(73.86 \%)$ belonged to lower class, followed by $16(18.18 \%)$ from the upper lower class. All the

\begin{tabular}{|l|l|}
\hline \multicolumn{2}{|l|}{$\begin{array}{l}\text { Table 3: Distribution of maternal deaths } \\
\text { by delivery characteristics }\end{array}$} \\
\hline Variables & $\begin{array}{l}\text { No. of maternal } \\
\text { deaths (\%) }\end{array}$ \\
\hline Parity & $62(70.45 \%)$ \\
\hline Primigravidas & $21(23.86 \%)$ \\
\hline Multigravidas (2-4) & $05(5.68 \%)$ \\
\hline Grand multi ( $>5)$ & $12(13.63 \%)$ \\
\hline Antenatal registration \\
\hline Booked & $76(86.36 \%)$ \\
\hline Unbooked & $02(2.27 \%)$ \\
\hline Stage of pregnancy at time of death \\
\hline 1st trimester & $02(2.27 \%)$ \\
\hline 2nd trimester & $23(26.13 \%)$ \\
\hline 3 rd trimester & $61(69.31 \%)$ \\
\hline Post- partum & 00 \\
\hline Abortion & $53(60.22 \%)$ \\
\hline Time interval from admission to death \\
\hline $0-6$ hrs & $21(23.86 \%)$ \\
\hline $7-12$ hrs & $09(10.22 \%)$ \\
\hline $13-24$ hrs & $5(5.68 \%)$ \\
\hline$>24$ hrs &
\end{tabular}

mothers who died were from rural areas. Majority 52 $(59.09 \%)$ of them were educated up to primary level followed by $22(25 \%)$ were illiterate and only 12 $(13.63 \%)$ had studied up to secondary level.

As seen from table 3, out of total 88 deaths, 62 $(70.45 \%)$ were primigravidas, $21(23.86 \%)$ were multigravidas, and $5(5.68 \%)$ were grand multipara. Maximum deaths, $76(86.36 \%)$ have occurred who were unbooked cases. Majority, 61(69.31\%) deaths occurred in post-partum period; followed by $23(26.13 \%)$ in the 3 rd trimester and $2(2.27 \%)$ in the 2 nd trimester and another 2(2.27\%) were expired with the diagnosis of ruptured ectopic pregnancy. As observed from table 3,

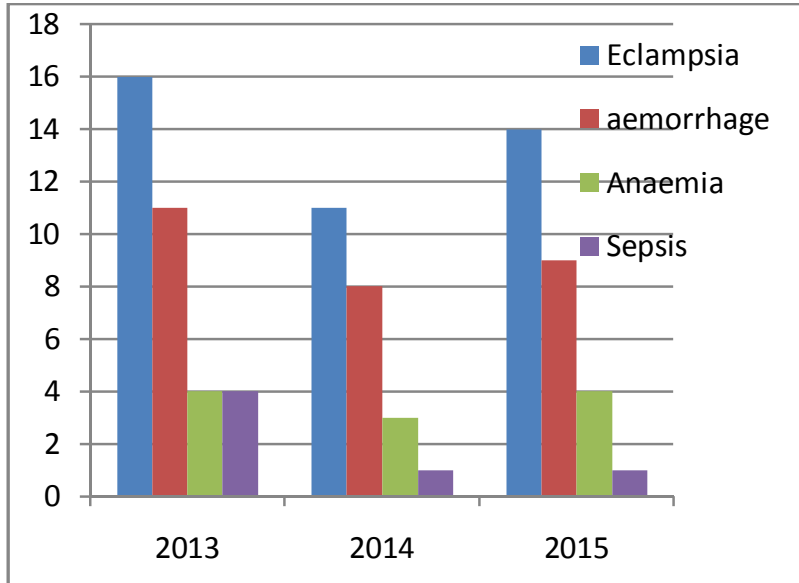

Figure 1: Distribution of causes of maternal mortality according to the year

out of 88 deaths, $53(60.22 \%)$ women died within 6 hour of admission and 21 (23.86\%) died between 7-12 hours of admission. Another 14 (15.90\%) died within the post partum period due to various complications. It is also seen from table 3 that, $9(10.22 \%)$ women died between 13-24 hours of admission and 5 (5.68\%) after 24 hours of admission.

As evident from figure 1, direct causes contributed to $86.36 \%(\mathrm{n}=76)$ of maternal deaths and indirect causes contributed to $13.63 \%(\mathrm{n}=12)$. Amongst the direct causes, $45.45 \%(n=40)$ of total maternal deaths

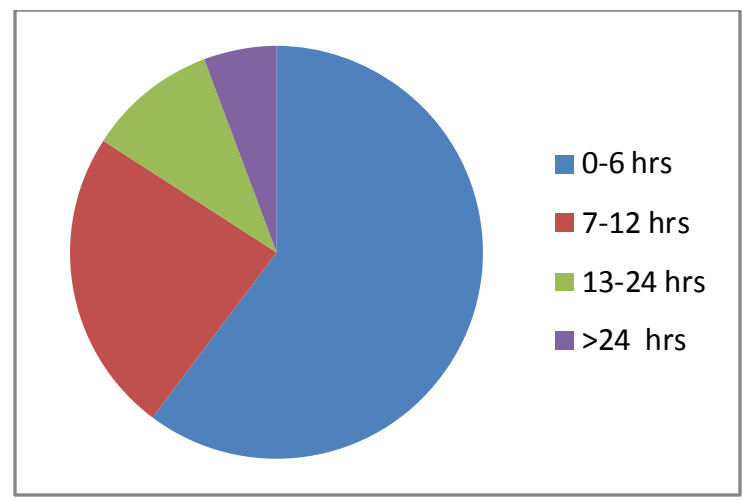

Figure2: Distribution of maternal deaths in relation to time interval from admission to death 
were due to eclampsia. Hemorrhage and sepsis were responsible for $31.81 \%(\mathrm{n}=28)$ and $6.87 \%(\mathrm{n}=6)$ of total maternal deaths respectively. Embolism accounted for $2.27 \%(\mathrm{n}=2)$ of the total maternal deaths. Amongst the indirect causes, anaemia accounted for $12.50 \%$ $(n=11)$ of total maternal deaths. The other indirect cause was renal failure $1.14 \%(n=1)$. The pie diagram as shown in figure 2 reflects the time interval between admission and death. It is shown that most of the maternal deaths occurred within six

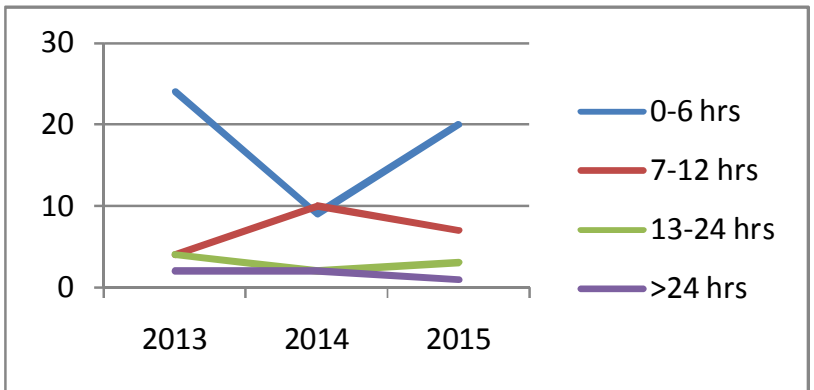

Figure 3: Distribution of maternal deaths year wise in relation to time interval from admission to death.

hours of admission followed deaths occurring within twelve hours of admission. This indicates that majority of the cases were referred to the tertiary centre at a very critical and irreversible stage which is quite late to save the mothers. It is also observed that this time interval is almost similar in all the three years. In our study a few number of maternal deaths were found to occur after twenty four hours of admission. Graphical representation in figure 3 also shows distribution of deaths per year in relation to the time interval between admission and death. It is observed in our study that the time interval from admission to death is similar in all the three years. This we can say is a very important factor for high maternal death as these mothers arrived at the tertiary care centre quite late and at a very critical and irreversible stage, which in most of the cases were due to late referral.

\section{Discussion}

Maternal mortality is unacceptably high in developing countries including India. Death of mother is a tragic event. In practical life, it has a severe impact on the family, community and eventually the nation. The young surviving children left motherless are unable to cope with daily living and are at an increased risk of death. Reduction of maternal mortality is the objective of MDGs, especially in low income countries, where one in 16 women die of pregnancy related complications.

In the present study, there were 88 maternal deaths amongst 20333 deliveries and 19716 live births, giving an MMR of 446.38 per 1,00,000 live births, which is higher than the national averages. Jorhat medical college and hospital being a teaching institution and a tertiary care centre, get complicated cases from rural areas. Admissions of moribund cases referred from peripheral hospital have inflated this mortality ratio, like other teaching institutions of India. Like this study, other similar studies from tertiary care institution reported MMR ranged between 213 to 879 per $1,00,000$ live births as described by A. Verma et al, $\mathrm{N}$. Purandare and A Pal et al [6-8].

No discussion of global maternal, newborn, and child health is complete without addressing basic issues of social determinants [9]. Marmot notes that, according to the World Health Organization, - Social determinants of health are the conditions in which people are born, grow, live, work, and age; these circumstances are shaped by the distribution of money, power and resources at global, national, and local levels [10]. In the present study, Maximum deaths $69(78.40 \%)$ were in the age group of below 25 years. Maternal deaths in age $<19$ years is $32(36.36 \%) \&$ over the age of 30 years is $6(6.1 \%)$. A study done by Dogra also showed similar age distribution like our study. With the prevailing custom of early marriage in rural area, majority of the women present with their pregnancy in the early age group. In the present study, out of 88 death $62(70.45 \%)$ were primigravidas and $21(23.86 \%)$ were multigravidas. In our study $5(5.68 \%)$ women were grand multipara. Dogra and Purandare also published similar report in their studies $[11,12]$. In the current study, maximum maternal deaths occurred in primigravidas. This is because most of the eclamptic patients were primigravida and eclampsia took the 
highest toll of maternal deaths. Too many and too close pregnancies also adversely affect the mother's health. In our study, majority of maternal deaths $86.36 \%$ $(n=76)$ occurred in unbooked cases. High incidence of deaths among the unbooked cases has also been observed in study done by Roy et al [13].

In our study, the highest mortality is observed among the marginalized and poor population, who frequently reside in remote and rural areas with limited access to health care services. Similar reports have been observed in their study done by Bhutta $\mathrm{AZ}$ and Black RE [9].

A delay in accessing health care can occur at three time points. This has been described as the three-delay model: the first delay refers to a woman or her family delaying the decision to seek care; the second is the delay in reaching that care; and the third is the delay in receiving care once a healthcare provider is reached which is described by Mullick SS in their study [14]. A similar pattern was also observed in this study.

In the present study, 53(60.22\%) women died within 6 hours of admission and 21(23.86\%) died between 6-12 hours of admission. In our study $9(10.22 \%)$ women died between 13-24 hours of admission and 5(5.68\%) women died after 24 hours of admission. In our study death within 6 hours is found more in comparison to reports published by Purandare in their study [12]. About 74(84.09\%) deaths occurred within 12 hours of admission suggesting majority patients reach the tertiary care hospital quite late. Strengthening of both basic and comprehensive emergency obstetrics care at primary health centre level and first referral unit could possibly save many mothers lives.

In the present study, maximum deaths $61(69.31 \%)$ occurred in the post-partum period, followed by $23(26.13 \%)$ in the 3rd trimester. Similar results have also been reported by other studies done by Dogra K, P. Gupta, N. Purandare and A. Singh [11,12]. High numbers of deaths in post-partum period indicate the need for continuous vigilance in post-partum period and prompt action in case of problems. Intranatal care by skilled attendant, timely management and replacement of lost blood volume can reduce deaths in post-partum period.

In the present study, direct causes contributed to $76(86.36 \%)$ of maternal deaths, of which eclampsia $40(45.45 \%)$ is the most Common cause. Other direct causes were hemorrhage $28(31.81 \%)$, sepsis $6(6.81 \%)$ and pulmonary embolism 2 (2.27\%). Indirect causes contributed to $12(13.63 \%)$ maternal deaths, of which anemia $11(12.50 \%)$ were the most common causes. Though eclampsia is preventable in almost all cases by good obstetrics care, it was found to be the leading cause of deaths $40(45.45 \%)$ in our institution. It is mainly due to high incidence of eclampsia in this area and delayed referral mostly after 12 hours of the incidence. Eclampsia, as seen in our study was found to be the leading cause of death in study done by Roy et al [13].

The high maternal mortality reported from the developing countries was noted primarily among patients who did not have prenatal care as described by RL Goldenberg and P. Desari [15-17] which is found similar with our study as most of our maternal deaths were found in unbooked cases.

The socioeconomic status, level of education, the quality of patients' nutrition and antenatal care of the patients in our study were very low. Lack of and/or poor prenatal care, delay in early diagnosis, progression to severe disease, delay in treatment, lack of access to hospital care, lack of access to transportation to hospital, lack of transport from hospital to tertiary facility, lack of well-trained staff and personal, lack of proper resources and Intensive care unit were responsible for high maternal mortality in our study. These results are comparable with the study done by Bangal [18].

Although the focus during the past decades has been on the saving of maternal lives, it is also important to look beyond survival to issues of reducing morbidity and disability and improving long-term outcomes of relevance to human development. The close links among poverty, inequity, under nutrition and human deprivation are well known, and all these factors have been shown to reduce the potential for human 
development considerably as shown in their study by AZ Bhutta and RE Black [9] which is comparable to our study also. There are promising interventions that can benefit survival as well as human development as shown in their study by LC Fernald and P L Engle [19] and there is a huge public health need to integrate the two issues which is concluded as take home message in our study also. Linking the agenda for maternal and child health and nutrition with the emerging issues of long-term development, human capital, and economic growth may well be the most appropriate strategy to ensure that we stay the course in solving one of the most important moral dilemmas of our times.

\section{Conclusion}

The MMR in this study is higher than the national average. Most deaths could have been avoided with the help of good antenatal, intranatal and postnatal care, early referral, quick, efficient and well equipped transport facilities, availability of adequate blood and blood components, adequate number of well equipped ICU beds at tertiary care level and by promoting overall safe motherhood. To reduce the maternal mortality and morbidity the main thrust should be on implementing basic and comprehensive emergency obstetrics care at peripheral level. Analysis of every maternal death through maternal death audit, at both community level (verbal autopsy) and at the institutional level should be carried out. It will help in identifying the actual causes of maternal death and deficiencies in health care delivery system that might contribute in formulating preventive measures to reduce pregnancy related deaths.

\section{Conflict of interest: None. Disclaimer: Nil.}

\section{References}

1. Countdown to 2015 for maternal, newborn and child survival: accountability for maternal, newborn anchild survival. Geneva: Who Health Organisation, 2013 (http//www.countdown2015mnch.org/documents/2013Re port/Countdown_2013-Updates_noprofiles.pdf).

2. Trends in maternal mortality: 1990-2010 - estimates developed by WHO, UNICEF, UNFPA and the World
Bank. 2012.

(http//www.unfpa.org/public/home/publications/pid/1072 $8)$.

3. World Health Organization and Unicef. Countdown to 2015 Decade Report (2000-2010): Taking Stock of Maternal, Newborn and Child Survival. Geneva: WHO and UNICEF, 2010

[http//www.childinfo.org/files/countdownReport 20002010.pdf] Accessed 17 August 2011.

4. Gurina NA, Vangen S, Forsen L, Sundby J. Maternal mortality in St. Petersburg, Russian Federation. Bull World Health Organization. 2006; 84: 283-9.

5. Lozano R, Wang H, Foreman KJ, et al. Progress towards Millennium Development goals 4 and 5 on maternal and child mortality: an updated systematic analysis. Lancet. 2011; 378:1139-65.

6. Pal A, Rai P, Hazara S, Mondal T K. Review of changing trends in Maternal Mortality in rural medical College in West Bengal. J Obstet Gynaecol India. 2005; 55: 521-25.

7. Purandare N, Singh A, Upahdya S, et al. Maternal mortality at a referral centre: a five year study. J obstet Gynaecol India. 2007; 57(3):248-50.

8. Verma A, Minhas S, Sood A. A study of Maternal Mortality. J. Obstet Gynaecol India. 2008; 58: 226-29.

9. Bhutta Z A, Black R E. Global Maternal, Newborn, and Child Health-So Near and Yet So Far. N Engl J Med. 2013; 369:2226-35.

10. Marmot M. Closing the health gap in a generation: the work of the Commission on Social Determinants of Health and its recommendations. Glob Health Promot. 2009; 16(Suppl 1):23-7.

11. Dogra P, Gupta K B. A study of maternal mortality at a tertiary institute. Obs. and Gynae Today. 2009; 115: 5860.

12. Purandare N, Singh A, Upadhyae S, Saraogi R M. Maternal Mortality at a referral centre: a five year study. J Obstet Gynaecol India. 2007; 57: 248-50

13. Roy S, Singh A, Pandey A, Roy H, Roy S, Roy S. Maternal Mortality in Apex Hospital of Bihar. J. Obstet Gynecol Ind. 2002; 52: 100-104.

14. Mullick SS, Serle E. Achieving millennium development goals 4 and 5: a snapshot of life in rural India. BJOG. 2011; 118 (Suppl. 2):104-7. 
15. Goldenberg RL, McClure EM, MacGuire ER, et al. Lessons for low-income regions following the reduction in hypertension-related maternal mortality in high-income countries. Int J Gynecol Obstet. 2011; 113: 91- 5 .

16. Danso KA, Opare-Addo HS. Challenges associated with hypertensive disease during pregnancy in lowincome countries. Int J Gynecol Obstet. 2010; 110:78-81.

17. Dasari P, Habeebullah S. Maternal mortality due to hypertensive disorders of pregnancy in a tertiary care center in Southern India. Int J Gynaecol Obstet. 2010; 110: 271-73.

18. Bangal VB, Giri PA, Garg R. Maternal Mortality at a Tertiary Care Teaching Hospital of Rural India: A
Retrospective Study. Int J Biol Med Res. 2011; 2(4): 1043 $-46$.

19. Engle PL, Fernald LC, Alderman H, et al. Strategies for reducing inequalities and improving developmental outcomes for young children in low-income and middleincome countries. Lancet 2011; 378:1339-53.

\section{Binoy Kumar Borah ${ }^{1}$, Nikhil Ranjan Rajkhowa ${ }^{2}$}

${ }^{1}$ Assistant Professor, Department of Obstetrics and Gynaecology, Jorhat Medical College, Jorhat, Assam; ${ }^{2}$ Assistant Professor, Department of Obstetrics and Gynaecology, Jorhat Medical College, Jorhat, Assam. 